\title{
Research on the Legal Responsibility of the Network Car Platform Company
}

\author{
Han Xiao \\ Wuhan Engineering Vocational and Technical College, Wuhan, Hubei, 430062
}

\begin{abstract}
Keywords: Network Car Platform Company, Legal Responsibility, Business Positioning
\end{abstract}
\begin{abstract}
Under the background of information network dataization, with the development and application of taxi software, it not only brought great impact to the traditional taxi industry in the past, but also led to the blank of the regulation of the network car market, making it many legal risks are hidden in the market operation process. This paper attempts to use the legal attributes of the network platform to identify the specific obligations of the platform, standardize the market access conditions for special vehicles and drivers, and provide a certain degree of theoretical research value for the legal protection of passenger rights.
\end{abstract}

\section{Introduction}

Since the rise of Internet taxi software in China, it has not only provided high-quality, diverse and differentiated services for the transportation market, but also solved the practical problem of "difficulty in taxis" in people's lives. However, technology is a double-edged sword. In the past, the academic community has been extremely controversial about the legitimacy of the network car, leading to the current gap in market regulation, which makes it hide many legal risks in the market operation process. Including the legal attributes of the network car platform is ambiguous, the platform's responsibility and liability are difficult to identify, passenger rights are not guaranteed, and so on. Therefore, the theoretical research on the network car is not only in line with the current trend of social hot issues, but also one of the key problems to be solved in China. However, since the taxi software has only begun to rise in recent years, the theoretical research on the network car is only in its infancy. The relevant materials can be found that most of the research focuses on the legal status of the network car and how to carry out administrative supervision. Some of the scholars will focus on the economic benefits brought by the network to the society, emphasizing that it has greater advantages and convenience than traditional taxis [1].

Of course, the current research on the market access rules and the protection of passenger rights and interests of the network car platform has also been expanded to a certain extent, especially the frequent occurrence of passengers' personal rights and interests in life, network traffic accidents and other similar cases. People have to pay attention to the protection of the legitimate rights and interests of passengers in the network, and re-examine the legal regulation of the platform and the safety of the network. Among them, the typical issues concerning the distribution of responsibility for traffic accidents involving the network car are: (1) The network car platform bears the responsibility of all carriers. The new rules for the network car clarify the labor relationship between the platform and the driver of the car. It also reflects the relationship between the passenger and the passenger. The platform company, that is, the tort liability after the accident, is undertaken by the platform company as the carrier. (2) The network car platform bears the responsibility. Some scholars believe that although the network car platform and the driver should be characterized as intermediation, but because the passenger operation has its own particularity, it has a higher risk than the general buying and selling behavior. At the same time, it must bear a certain degree or more of responsibility. The platform operator must at least be liable to the passengers based on the profit share. (3) The network car platform and the car driver bear joint and several liability. The academic community has some opinions to support the network car platform should be responsible for the passengers together with the car driver, and bear joint and several liability when personal injury is caused by the infringement. [2] For example, joint liability for failure to accurately provide the identity information of the owner of the vehicle and joint liability for failure to take necessary 
measures due to "knowing or knowing” the risk of infringement.

\section{The Meaning of the Network Car}

Net-based car refers to the creation of a service platform based on Internet information technology, which integrates and matches the information of passengers and car owners, realizes the effective docking of supply and demand, and enables qualified car owners to carry out non-traveling appointments for car rental services. Generally speaking, its operation mode is: the network reservation taxi operator (hereinafter referred to as the network car platform company) launched the taxi software, the passenger downloads the taxi software through the mobile phone, after registering the account, input the origin and destination on the software. Choose whether to pay the tip and tip amount (the tip amount generally ranges from 5 yuan to 20 yuan), wait for the driver to take the order, and the passenger can settle the payment through Alipay, WeChat or other means after arriving at the destination, or negotiate with the driver for other payment methods. . The whole process is operated by mobile phone.

\section{The Legal Regulation of Network Car Platform as the Carrier}

After the theoretical analysis of the previous article, the legal attributes of the network car platform should be defined according to different operating modes. When a network driver is employed as a full-time employee in a platform company, there is a labor contract legal relationship between the driver and the platform. On this basis, the platform establishes a passenger transportation service contract with the passengers as the carrier. It should not only bear the carrier's responsibility, but also bear relatively strict obligations in the management of the operating vehicle and the driver and the operation of the company. This will be the focus of this chapter for specific research.

In order to regulate the operation activities of the network car, it is necessary to regulate the market access rules of the network car platform, including not only the operating qualification of the platform company itself, but also the network car vehicles and drivers directly managed by the platform to ensure that only certain Conditions can be officially operated in the market, which is undoubtedly an important prerequisite for the protection of passenger rights and interests. Previously, due to the fact that the network car was always in an "illegal" state and lacked the control of the relevant legal system, the qualifications of operating vehicles and drivers were uneven. Nowadays, with the promulgation of the Interim Measures for the Network Cars, it has a constructive view on the market access of the network car platform. However, the author believes that there are still places for further improvement and discussion [3].

In order to engage in specific business activities, the network car platform must first meet the corresponding conditions for establishment, and after formal procedures, register with the administrative department stipulated by law and obtain legal person status. However, in the past period of time, the network car has been labeled as "illegal business", until the "Interim Measures for Internet Cars" issued in July this year for the first time confirmed the legality of the operation of the network car, the network About the car platform company is qualified to reserve a taxi operator for the network, and has the legal person qualification to engage in online car business services. Therefore, the platform company should obtain the business license issued by the relevant department. It should be emphasized that the author believes that the definition of the platform company and the related access conditions are only applicable to the network car operation mode when the platform is self-supplied. The establishment of the network car platform company should not only have the human conditions, that is, the requirements for the number of shareholders and promoters of the company and the qualifications of the promoters, but also the necessary material conditions necessary for the establishment of the company. In addition, the establishment of the network car platform company must also comply with the law, which mainly includes the formulation of the charter, the choice of company name, the determination of the organization.

The Interim Measures for Internet Vehicles stipulates that a platform company engaged in the 
transportation service of passengers on the network should have the business license of the enterprise legal person, and obtain the corresponding business license, and apply to the competent department for filing before proceeding with the relevant business. For the vehicles and drivers provided, the network car platform should be properly checked and reported, and the vehicles providing the services must have legal operating qualifications, stable and safe performance, and certain insurance measures. The driver who provides the service is guaranteed to have a good driving skill and good professional quality, which is in line with the conditions for the operation of the network. Ensure that drivers and vehicles participating in online and offline car activities are consistent.

The network car platform company shall maintain and protect the legitimate rights and interests of the driver, and carry out pre-job training and daily education on relevant laws and regulations, professional ethics, service standards, and safety operations. This is not only a basic right of the network driver, but also the platform company has the obligation to train and educate its employees. Because the platform and the driver belong to the legal relationship of the labor contract at this time, the platform company, as the employer, has certain management and care responsibility for the staff members it belongs to. In order to better engage in the operation of the network car, the driver should be provided with relevant vocational training before the passenger transportation service is provided. This also has similar mandatory provisions in the Labor Law of China. In addition to the above-mentioned statutory operational obligations, the platform companies engaged in the operation of network-related vehicles should also comply with the relevant laws and regulations of China and the relevant regulations on the management methods of online vehicles, and strictly abide by the market order. That is, the platform must not operate at a price lower than the cost, do not abuse the market position to crowd out competitors, prohibit any monopolistic behavior that hinders fair competition in the market, and prohibit any unfair practices that disrupt the market order. If there is any prohibited behavior that damages the national interest or the public interest of the society, infringes upon the legitimate rights and interests of passengers and the legitimate rights and interests of other operators, the network car platform must bear the corresponding legal responsibilities [3].

The network car platform must guarantee the authenticity and legitimacy of the relevant business information in its service platform, and must not publish information that is prohibited by laws and regulations. At the same time, it is not allowed to publish false advertisements in business activities, make a promise that the network car service does not conform to the actual situation, and prohibit any behavior that may lead to misunderstanding of passengers. Because ordinary passengers have cognitive limitations on this service, and consumers in the network environment have certain dependence and trust on the information provided by operators, it is easy for passengers to misunderstand or even be deceived when trading. Its legal rights and interests have been violated. In this regard, China's "Consumer Rights Protection Law" also made clear provisions. For example, Article 8 stipulates: "The right of consumers to know the true feelings, consumers have the right to know the truth about the goods they buy or use or the services they receive"; Article 19 states: "The operators have the true information. The obligation of the operator shall provide the consumer with real information about the goods or services, and shall not make false propaganda that is misleading." This is equally applicable to the network car activities. Therefore, the network car platform should not exaggerate the facts during the promotion process, and prohibit acts that harm the interests of passengers.

\section{The Network Car Platform as a Legal Regulation of the Intermediary}

When the platform company acts as an intermediator for the network car operation, since it does not directly participate in the actual passenger transportation service, the network car platform and the driver or passenger only belong to the intermediation legal relationship. A private car owner with operational qualifications will form a direct commercial relationship with the passengers. This is similar to a self-employed taxi. At this time, the private car owner should be responsible for the casualties of the passenger. The responsibility of the platform company is much less than that of the 
labor contract model. However, this does not mean that the platform does not have any legal obligations. In the course of its operation, it must fulfill its obligation to inform passengers of its attributes. If it is not performed properly or the passenger mistakenly believes that the private car belongs to the platform company, the platform still has to bear certain responsibility [4].

The newly issued "Interim Measures for Internet Cars" unified the platform company as the main business of the network car service, and regulated the market access conditions of its vehicles and drivers, but ignored the differences in different operating modes, resulting in the platform. The legal attributes do not correspond to their obligations, which is also an unreasonable part of the management approach. Because, if the platform company is only an intermediary between the driver and the passenger, it does not directly participate in the carrier service; and the private car that is joined is also provided by the driver, then the vehicle and the driver are not subordinate to the platform company from a legal point of view. The platform company has no corresponding management obligations. In this case, in order to make the private car have certain operational qualifications, the driver of the owner or the affiliated car should have the obligation to ensure that it meets the corresponding qualifications, and must pass the review and evaluation of the relevant department, and only obtain the administrative authority. In other words, the entry conditions for private cars engaged in online car service are higher, and the qualifications and related requirements of drivers will also be improved [5].

\section{Conclusion}

The network car has developed very rapidly in the past two years, which is inseparable from the advanced technology of mobile networks and smart phones, but the pace of the law has not kept up with the changes in the development of the Internet. The network car activity is actually the integration of information about booking a car rental through the Internet, in order to provide fast travel services. From the perspective of the network car platform, this paper analyzes the controversial problems of the current network car through actual cases. The most important issue is to clarify the legal relationship of the network car and clarify the legal attributes of the platform. This is also the basis for constructing the platform legal regulation system.

\section{Acknowledgements}

Fund Project: Hubei Provincial Department of Education research project, network car platform company's business positioning and legal responsibility

\section{References}

[1] Fang Lunan, Jiang Liping, Dong Xinghui. Responsibility identification of taxi traffic accidents in the network [J]. Legal Expo, 2016: 28-33.

[2] Cao Dayou, Peng Qianwen. Is it a labor relationship or a labor relationship?_—Analysis of the employment relationship of the Internet car rental platform in the Chinese context with the example of Drips[J].China Human Resources Development,2016,02:96.

[3] Gu Wei. On the legal relationship between the network platform and the driver of the car [J]. Legal System and Society, 2016 (05): 80-82.

[4] Lu Xin. Exploring the legal relationship between the driver of the car and the platform of the taxi software [J]. Legal Expo, 2016 (02).95

[5] LIU Shuzheng, HUANG Gongxing, ZHANG Dong. Research on the main body of traffic accidents in the process of car rental[J]. Economics and Law,2010(05).66 